\title{
Fixed points of some new contractions on intuitionistic fuzzy metric spaces
}

\author{
Cristiana Ionescu ${ }^{1 *}$, Shahram Rezapour ${ }^{2}$ and Mohamad Esmaeil Samei
}

\section{"Correspondence:}

cristianaionescu58@yahoo.com

'Department of Mathematics,

Azarbaijan University of Shahid

Madani, Azarshahr, Tabriz, Iran

Full list of author information is

available at the end of the article

\begin{abstract}
We introduce some new contractions on intuitionistic fuzzy metric spaces, and give fixed point results for these classes of contractions. A stability result is established.
\end{abstract}

Keywords: contractive mapping; fixed point; intuitionistic metric space

\section{Introduction and preliminaries}

The great interest in the study of various fixed point theories for different classes of contractions on some specific spaces is known. We underline studies on quasi-metric spaces [1, 2], quasi-partial metric spaces [3], convex metric spaces [4], cone metric spaces [5-7], partially ordered metric spaces [8-17], partial metric spaces [18], Menger spaces [19], Gmetric spaces [20, 21], and fuzzy metric spaces [22-25].

The concept of fuzzy set was introduced by Zadeh in 1965 [26]. Ten years later, Kramosil and Michalek introduced the notion of fuzzy metric spaces [24] and George and Veeramani modified the concept in 1994 [27]. Also, they defined the notion of Hausdorff topology in fuzzy metric spaces [27].

In 2004, Park introduced the notion of intuitionistic fuzzy metric space. In his elegant article [28], he showed that for each intuitionistic fuzzy metric space $(X, M, N, *, \diamond)$, the topology generated by the intuitionistic fuzzy metric $(M, N)$ coincides with the topology generated by the fuzzy metric $M$.

Actually, Park's notion is useful in modeling some phenomena where it is necessary to study the relationship between two probability functions. Some authors have introduced and discussed several notions of intuitionistic fuzzy metric spaces in different ways (see, for example, [29-31]. Grabiec obtained a fuzzy version of the Banach contraction principle in fuzzy metric spaces in Kramosil and Michalek's sense [22], and since then many authors have proved fixed point theorems in fuzzy metric spaces [32-35].

For necessary notions to our results, such as continuous $t$-norm, intuitionistic fuzzy metric space and the induced topology, which is denoted by $\tau_{(M, N)}$, we refer the reader to [28] and [36].

A sequence $\left\{x_{n}\right\}$ in an intuitionistic fuzzy metric space $(X, M, N, *, \diamond)$ is said to be Cauchy sequence whenever, for each $\varepsilon>0$ and $t>0$, there exists a natural number $n_{0}$ such that $M\left(x_{n}, x_{m}, t\right)>1-\varepsilon$ and $N\left(x_{n}, x_{m}, t\right)<\varepsilon$ for all $n, m \geq n_{0}$.

The space $(X, M, N, *, \diamond)$ is called complete whenever every Cauchy sequence is convergent with respect to the topology $\tau_{(M, N)}$.

(c) 2013 lonescu et al:; licensee Springer. This is an Open Access article distributed under the terms of the Creative Commons Attribution License (http://creativecommons.org/licenses/by/2.0), which permits unrestricted use, distribution, and reproduction in any medium, provided the original work is properly cited. 
Let $(X, M, N, *, \diamond)$ be an intuitionistic fuzzy metric space. According to [32], the fuzzy metric $(M, N)$ is called triangular whenever

$$
\frac{1}{M(x, y, t)}-1 \leq \frac{1}{M(x, z, t)}-1+\frac{1}{M(z, y, t)}-1
$$

and

$$
N(x, y, t) \leq N(x, z, t)+N(z, y, t)
$$

for all $x, y, z \in X$ and $t>0$.

We shall use the above background to develop our new results in this article. Our results are stated on complete triangular intuitionistic fuzzy metric spaces. In this framework, we introduce some new classes of contractive conditions and give fixed point results for them.

\section{Main results}

Now, we are ready to state and prove our main results.

Theorem 2.1 Let $(X, M, N, *, \diamond)$ be a complete triangular intuitionistic fuzzy metric space, $h \in[0,1)$ and let $T: X \rightarrow X$ be a continuous mapping satisfying the contractive condition

$$
\frac{1}{M(T x, T y, t)}-1 \leq h \max \left\{\frac{1}{M(x, T x, t)}-1, \frac{1}{M(y, T y, t)}-1\right\}
$$

for all $x, y \in X$. Then $T$ has a fixed point.

Proof Let $x_{0} \in X$. Put $x_{1}=T x_{0}$ and $x_{n+1}=T^{n+1} x_{0}$ for all $n \geq 1$.

If $x_{n}=x_{n+1}$ for some $n$, then we have nothing to prove.

Assume that $x_{n} \neq x_{n+1}$ for all $n$. Then

$$
\begin{aligned}
\frac{1}{M\left(x_{n+1}, x_{n}, t\right)}-1 & =\frac{1}{M\left(T x_{n}, T x_{n-1}, t\right)}-1 \\
& \leq h \max \left\{\frac{1}{M\left(x_{n}, T x_{n}, t\right)}-1, \frac{1}{M\left(x_{n-1}, T x_{n-1}, t\right)}-1\right\}
\end{aligned}
$$

for all $n$.

Now, for each $n$, put $t_{n}=\max \left\{\frac{1}{M\left(x_{n}, T x_{n}, t\right)}-1, \frac{1}{M\left(x_{n-1}, T x_{n-1}, t\right)}-1\right\}$.

If $t_{n}=\frac{1}{M\left(x_{n}, T x_{n}, t\right)}-1$, then

$$
\frac{1}{M\left(x_{n+1}, x_{n}, t\right)}-1 \leq h\left(\frac{1}{M\left(x_{n}, T x_{n}, t\right)}-1\right)=h\left(\frac{1}{M\left(x_{n}, x_{n+1}, t\right)}-1\right),
$$

which is a contradiction. Thus, $t_{n}=\frac{1}{M\left(x_{n-1}, T x_{n-1}, t\right)}-1$ for all $n$, and so

$$
\frac{1}{M\left(x_{n+1}, x_{n}, t\right)}-1 \leq h\left(\frac{1}{M\left(x_{n-1}, T x_{n-1}, t\right)}-1\right) .
$$


But

$$
\begin{aligned}
\frac{1}{M\left(x_{n}, x_{n-1}, t\right)}-1 & =\frac{1}{M\left(T x_{n-1}, T x_{n-2}, t\right)}-1 \\
& \leq h \max \left\{\frac{1}{M\left(x_{n-1}, T x_{n-1}, t\right)}-1, \frac{1}{M\left(x_{n-2}, T x_{n-2}, t\right)}-1\right\}
\end{aligned}
$$

and $\frac{1}{M\left(x_{n}, x_{n-1}, t\right)}-1 \leq h\left(\frac{1}{M\left(x_{n-2}, T x_{n-2}, t\right)}-1\right)$ for all $n$.

Thus,

$$
\frac{1}{M\left(x_{n+1}, x_{n}, t\right)}-1 \leq h\left(\frac{1}{M\left(x_{n}, x_{n-1}, t\right)}-1\right) \leq \cdots \leq h^{n}\left(\frac{1}{M\left(x_{1}, x_{0}, t\right)}-1\right)
$$

Hence, for each $n>m$, we obtain

$$
\begin{aligned}
\frac{1}{M\left(x_{n}, x_{m}, t\right)}-1 & \leq \frac{1}{M\left(x_{n}, x_{n-1}, t\right)}-1+\cdots+\frac{1}{M\left(x_{m+1}, x_{m}, t\right)}-1 \\
& \leq\left(h^{n-1}+h^{n-2}+\cdots+h^{m}\right)\left(\frac{1}{M\left(x_{1}, x_{0}, t\right)}-1\right) \\
& \leq \frac{h^{m}}{1-h}\left(\frac{1}{M\left(x_{1}, x_{0}, t\right)}-1\right)
\end{aligned}
$$

Therefore, $\left\{x_{n}\right\}$ is a Cauchy sequence and so there exists $x^{*} \in X$ such that $x_{n} \rightarrow x^{*}$. Since $T$ is continuous, $x_{n+1}=T x_{n} \rightarrow T x^{*}$ and so $x^{*}=T x^{*}$.

Theorem 2.2 Let $(X, M, N, *, \diamond)$ be a complete triangular intuitionistic fuzzy metric space and let $T: X \rightarrow X$ be a selfmap which satisfies the contractive condition

$$
\frac{1}{M(T x, T y, t)}-1 \leq\left[\frac{\frac{1}{M(x, T y, t)}-1+\frac{1}{M(y, T x, t)}-1}{\frac{1}{M(x, T x, t)}-1+\frac{1}{M(y, T y, t)}-1+\frac{1}{t}}\right]\left(\frac{1}{M(x, y, t)}-1\right)
$$

for all $x, y \in X$. Then $T$ has a fixed point.

Proof Let $x_{0} \in X$. Define the sequence $\left\{x_{n}\right\}$ by $x_{n+1}=T x_{n}$ for all $n$. Then

$$
\begin{aligned}
& \frac{1}{M\left(x_{n+1}, x_{n}, t\right)}-1=\frac{1}{M\left(T x_{n}, T x_{n-1}, t\right)}-1 \\
& \leq\left[\frac{\frac{1}{M\left(x_{n}, x_{n}, t\right)}-1+\frac{1}{M\left(x_{n-1}, x_{n+1}, t\right)}-1}{\frac{1}{M\left(x_{n}, x_{n+1}, t\right)}-1+\frac{1}{M\left(x_{n-1}, x_{n}, t\right)}-1+\frac{1}{t}}\right]\left(\frac{1}{M\left(x_{n}, x_{n-1}, t\right)}-1\right) \\
& =\left[\frac{\frac{1}{M\left(x_{n-1}, x_{n+1}, t\right)}-1}{\frac{1}{M\left(x_{n}, x_{n+1}, t\right)}-1+\frac{1}{M\left(x_{n-1}, x_{n}, t\right)}-1+\frac{1}{t}}\right]\left(\frac{1}{M\left(x_{n}, x_{n-1}, t\right)}-1\right) \\
& \leq\left[\frac{\frac{1}{M\left(x_{n-1}, x_{n}, t\right)}-1+\frac{1}{M\left(x_{n}, x_{n+1}, t\right)}-1}{\frac{1}{M\left(x_{n}, x_{n+1}, t\right)}-1+\frac{1}{M\left(x_{n-1}, x_{n}, t\right)}-1+\frac{1}{t}}\right]\left(\frac{1}{M\left(x_{n}, x_{n-1}, t\right)}-1\right) \\
& \leq \frac{1}{M\left(x_{n}, x_{n-1}, t\right)}-1
\end{aligned}
$$

for all $n$ and $t>0$. Therefore, $\left\{\frac{1}{M\left(x_{n}, x_{n-1}, t\right)}-1\right\}$ is a non-increasing sequence and so it is convergent to some $r \geq 0$. 
If $r>0$, then by putting

$$
\beta_{n}=\left[\frac{\frac{1}{M\left(x_{n-1}, x_{n}, t\right)}-1+\frac{1}{M\left(x_{n}, x_{n+1}, t\right)}-1}{\frac{1}{M\left(x_{n}, x_{n+1}, t\right)}-1+\frac{1}{M\left(x_{n-1}, x_{n}, t\right)}-1+\frac{1}{t}}\right],
$$

we obtain $\lim _{n \rightarrow \infty} \beta_{n}=\frac{2 r}{2 r+\frac{1}{t}}$ and so $r \leq \frac{2 r}{2 r+\frac{1}{t}} r$, which is a contradiction. Thus, $r=0$.

Note that

$$
\begin{aligned}
\frac{1}{M\left(x_{n+1}, x_{n}, t\right)}-1 & \leq \beta_{n}\left[\frac{1}{M\left(x_{n}, x_{n-1}, t\right)}-1\right] \leq \beta_{n} \beta_{n-1}\left[\frac{1}{M\left(x_{n-1}, x_{n-2}, t\right)}-1\right] \\
& \leq \cdots \leq\left(\beta_{n} \beta_{n-1} \cdots \beta_{1}\right)\left[\frac{1}{M\left(x_{1}, x_{0}, t\right)}-1\right]
\end{aligned}
$$

for all $n$. Thus, for each $m>n$, we get

$$
\begin{aligned}
& \quad \frac{1}{M\left(x_{m}, x_{n}, t\right)}-1 \\
& \quad \leq \frac{1}{M\left(x_{n}, x_{n+1}, t\right)}-1+\frac{1}{M\left(x_{n+1}, x_{n+2}, t\right)}-1+\cdots+\frac{1}{M\left(x_{m-1}, x_{m}, t\right)}-1 \\
& \quad \leq\left[\left(\beta_{n} \beta_{n-1} \cdots \beta_{1}\right)+\left(\beta_{n+1} \beta_{n} \cdots \beta_{1}\right)+\cdots+\left(\beta_{m-1} \beta_{m-2} \cdots \beta_{1}\right)\right]\left(\frac{1}{M\left(x_{1}, x_{0}, t\right)}-1\right) .
\end{aligned}
$$

Now, we consider $a_{n}=\beta_{n-1} \cdots \beta_{2} \beta_{1}$. Since $\lim _{n \rightarrow \infty} \frac{a_{n+1}}{a_{n}}=\lim _{n \rightarrow \infty} \beta_{n}=0$, it follows that $\sum_{k=1}^{\infty} a_{k}<\infty$. Hence, $\left\{x_{n}\right\}$ is a Cauchy sequence and so it converges to some $x^{*} \in X$.

We claim that $x^{*}$ is a fixed point of $T$.

Since

$$
\frac{1}{M\left(x_{n+1}, T x^{*}, t\right)}-1 \leq\left[\frac{\frac{1}{M\left(x_{n}, T x^{*}, t\right)}-1+\frac{1}{M\left(x^{*}, T x_{n}, t\right)}-1}{\frac{1}{M\left(x^{*}, T x^{*}, t\right)}-1+\frac{1}{M\left(x_{n}, T x_{n}, t\right)}-1+\frac{1}{t}}\right]\left(\frac{1}{M\left(x_{n}, x^{*}, t\right)}-1\right)
$$

for all $n$, we get $\frac{1}{M\left(x^{*}, T x^{*}, t\right)}-1=0$ and so $T x^{*}=x^{*}$.

The following example shows that there are discontinuous mappings which satisfy the conditions of Theorem 2.2 .

Example 2.1 Let $X=[0,2-\sqrt{3})$ endowed with the usual distance $d(x, y)=|x-y|$. Consider $M(x, y, t)=\frac{t}{t+d(x, y)}$ and $N(x, y, t)=\frac{d(x, y)}{t+d(x, y)}$ for all $x, y \in X$ and $t \geq 0$. Define the selfmap $T$ on $X$ by

$$
T x= \begin{cases}0, & x \in[0,2-\sqrt{3}) \\ 2-\sqrt{3}, & x=2-\sqrt{3}\end{cases}
$$

It is easy to check that $T$ satisfies the conditions of Theorem 2.2.

In fact, for $x=2-\sqrt{3}$ and $0 \leq y<2-\sqrt{3}$, we have

$$
\begin{aligned}
& \left(\frac{1}{M(T x, T y, t)}-1\right)\left[\frac{1}{M(x, T x, t)}-1+\frac{1}{M(y, T y, t)}-1+\frac{1}{t}\right] \\
& \quad=\left(\frac{|T x-T y|}{t}\right)\left[\frac{|x-T x|}{t}+\frac{|y-T y|}{t}+\frac{1}{t}\right]=\frac{2-\sqrt{3}}{t}\left[\frac{y}{t}+\frac{1}{t}\right]
\end{aligned}
$$




$$
\begin{aligned}
& \leq \frac{1}{t^{2}}\left[(2-\sqrt{3}-y)^{2}-(2-\sqrt{3})(2-\sqrt{3}-y)\right] \\
& =\left[\frac{|x-T y|}{t}+\frac{|y-T x|}{t}\right] \frac{|x-y|}{t} \\
& =\left[\frac{1}{M(x, T y, t)}-1+\frac{1}{M(y, T x, t)}-1\right]\left(\frac{1}{M(x, y, t)}-1\right),
\end{aligned}
$$

and so

$$
\frac{1}{M(T x, T y, t)}-1 \leq\left[\frac{\frac{1}{M(x, T y, t)}-1+\frac{1}{M(y, T x, t)}-1}{\frac{1}{M(x, T x, t)}-1+\frac{1}{M(y, T y, t)}-1+\frac{1}{t}}\right]\left(\frac{1}{M(x, y, t)}-1\right) .
$$

Theorem 2.3 Let $(X, M, N, *, \diamond)$ be a complete triangular intuitionistic fuzzy metric space, $\alpha, \beta \in[0,1)$ with $\alpha+\beta<1$ and let $T: X \rightarrow X$ be a continuous mapping which satisfies the contractive condition

$$
\frac{1}{M(T x, T y, t)}-1 \leq \alpha \frac{\left(\frac{1}{M(x, T x, t)}-1\right)\left(\frac{1}{M(y, T y, t)}-1\right)}{\frac{1}{M(x, y, t)}-1}+\beta\left(\frac{1}{M(x, y, t)}-1\right)
$$

for all $x, y \in X$. Then $T$ has a unique fixed point in $X$.

Proof Let $x_{0} \in X$. Put $x_{1}=T x_{0}$ and $x_{n+1}=T^{n+1} x_{0}$ for all $n \geq 1$.

If $x_{n}=x_{n+1}$ for some $n$, then we have nothing to prove.

Assume that $x_{n} \neq x_{n+1}$ for all $n$. Then

$$
\begin{aligned}
\frac{1}{M\left(x_{n+1}, x_{n}, t\right)}-1 & =\frac{1}{M\left(T x_{n}, T x_{n-1}, t\right)}-1 \\
& \leq \alpha \frac{\left(\frac{1}{M\left(x_{n}, T x_{n}, t\right)}-1\right)\left(\frac{1}{M\left(x_{n-1}, T x_{n-1}, t\right)}-1\right)}{\frac{1}{M\left(x_{n}, x_{n-1}, t\right)}-1}+\beta\left(\frac{1}{M\left(x_{n}, x_{n-1}, t\right)}-1\right),
\end{aligned}
$$

and so

$$
\begin{aligned}
\frac{1}{M\left(x_{n+1}, x_{n}, t\right)}-1 & \leq\left(\frac{\beta}{1-\alpha}\right)\left(\frac{1}{M\left(x_{n}, x_{n-1}, t\right)}-1\right) \\
& \leq \cdots \leq\left(\frac{\beta}{1-\alpha}\right)^{n}\left(\frac{1}{M\left(x_{1}, x_{0}, t\right)}-1\right)
\end{aligned}
$$

for all $n$.

By using the triangular inequality, for each $m \geq n$, we obtain

$$
\begin{aligned}
\frac{1}{M\left(x_{n}, x_{m}, t\right)}-1 & \leq \frac{1}{M\left(x_{n}, x_{n+1}, t\right)}-1+\frac{1}{M\left(x_{n+1}, x_{n+2}, t\right)}-1+\cdots+\frac{1}{M\left(x_{m-1}, x_{m}, t\right)}-1 \\
& \leq\left(k^{n}+k^{n+1}+\cdots+k^{m-1}\right)\left(\frac{1}{M\left(x_{0}, T x_{0}, t\right)}-1\right) \\
& \leq \frac{k^{n}}{1-k}\left(\frac{1}{M\left(x_{0}, T x_{0}, t\right)}-1\right),
\end{aligned}
$$

where $k=\frac{\beta}{1-\alpha}$. Thus, $\left\{x_{n}\right\}$ is a Cauchy sequence, therefore it converges to some $x^{*} \in X$. Since $t$ is continuous, it follows $T x^{*}=x^{*}$, hence $x^{*}$ is a fixed point of $T$. 
Now, suppose that $T$ has another fixed point $y^{*} \neq x^{*}$. Then we have

$$
\begin{aligned}
\frac{1}{M\left(x^{*}, y^{*}, t\right)}-1 & =\frac{1}{M\left(T x^{*}, T y^{*}, t\right)}-1 \\
& \leq \alpha \frac{\left(\frac{1}{M\left(y^{*}, T y^{*}, t\right)}-1\right)\left(\frac{1}{M\left(x^{*}, T x^{*}, t\right)}-1\right)}{\frac{1}{M\left(x^{*}, y^{*}, t\right)}-1}+\beta\left(\frac{1}{M\left(x^{*}, y^{*}, t\right)}-1\right) \\
& =\beta\left(\frac{1}{M\left(x^{*}, y^{*}, t\right)}-1\right)<\left(\frac{1}{M\left(x^{*}, y^{*}, t\right)}-1\right),
\end{aligned}
$$

which is a contradiction. Hence, $T$ has a unique fixed point.

We would like to prove that the iterative process utilized above is stable [4, 37]. More accurately, we need this definition.

Definition 2.1 On an intuitionistic fuzzy metric space $(X, M, N, *, \diamond)$, consider $T$ a selfmap on $X$, with a fixed point $p$. For $x_{0} \in X$, consider the Picard iteration, $x_{n+1}=T x_{n}$, which converges to $p$. Let $\left(y_{n}\right)$ be an arbitrary sequence in $X$. If

$$
\left[\left(M\left(y_{n+1}, T y_{n}, t\right) \rightarrow 1\right) \wedge\left(N\left(y_{n+1}, T y_{n}, t\right) \rightarrow 0\right)\right] \quad \Longrightarrow \quad y_{n} \rightarrow p
$$

we say that the Picard iteration is T-stable.

Corollary 2.1 Provided that the conditions of Theorem 2.3 are fulfilled, suppose that $p$ is the unique fixed point of T. Then the Picard iteration is T-stable.

Proof Indeed, using the triangular condition, we get

$$
\begin{aligned}
& \frac{1}{M\left(y_{n+1}, p, t\right)}-1 \\
& \leq \frac{1}{M\left(y_{n+1}, T y_{n}, t\right)}-1+\frac{1}{M\left(T y_{n}, T p, t\right)}-1 \\
& \leq \frac{1}{M\left(y_{n+1}, T y_{n}, t\right)}-1+\alpha \frac{\left(\frac{1}{M\left(y_{n}, T y_{n}, t\right)}-1\right)\left(\frac{1}{M(p, T p, t)}-1\right)}{\frac{1}{M\left(y_{n}, p, t\right)}-1}+\beta\left(\frac{1}{M\left(y_{n}, p, t\right)}-1\right) \\
& =\frac{1}{M\left(y_{n+1}, T y_{n}, t\right)}-1+\beta\left(\frac{1}{M\left(y_{n}, p, t\right)}-1\right)
\end{aligned}
$$

and so

$$
\frac{1}{M\left(y_{n+1}, p, t\right)}-1 \leq \frac{1}{M\left(y_{n+1}, T y_{n}, t\right)}-1+\beta\left(\frac{1}{M\left(y_{n}, p, t\right)}-1\right) .
$$

Now, we have to interpret this relation in terms of real sequences. For this purpose, we need the following result, [38].

Lemma 2.1 Let us consider $\delta \in[0,1)$ to be a real number and $\left\{\varepsilon_{n}\right\}$ to be a sequence of positive numbers such that $\lim \varepsilon_{n}=0$. If $\left\{u_{n}\right\}$ is a sequence of positive real numbers such that $u_{n+1} \leq \delta u_{n}+\varepsilon_{n}$, then $\lim u_{n}=0$.

Using Lemma 2.1 it follows that $\lim _{n \rightarrow \infty} y_{n}=p$, and the corollary is proved. 


\section{Conclusion}

In this work, we introduced some classes of contractive conditions on intuitionistic fuzzy metric spaces endowed with triangular metric. With additional condition of completeness, we introduced new fixed point results for these classes of mappings. A stability result is established.

\section{Competing interests}

The authors declare that they have no competing interests.

\section{Authors' contributions}

The authors completed the paper together. All authors read and approved the final manuscript.

\section{Author details}

${ }^{1}$ Department of Mathematics, Azarbaijan University of Shahid Madani, Azarshahr, Tabriz, Iran. ${ }^{2}$ Faculty of Applied Sciences, University Politehnica of Bucharest, 313 Splaiul Independenţei, Bucharest, 060042, Romania.

\section{Acknowledgements}

The authors thank the referees for their remarks on the first version of our article.

Received: 21 March 2013 Accepted: 3 June 2013 Published: 26 June 2013

\section{References}

1. Caristi, J: Fixed point theorems for mapping satisfying inwardness conditions. Trans. Am. Math. Soc. 215, 241-251 (1976)

2. Hicks, TL: Fixed point theorems for quasi-metric spaces. Math. Jpn. 33, 231-236 (1988)

3. Shatanawi, W, Pitea, A: Some coupled fixed point theorems in quasi-partial metric spaces. Fixed Point Theory Appl. 2013, ID 153 (2013)

4. Olatinwo, MO, Postolache, M: Stability results for Jungck-type iterative processes in convex metric spaces. Appl. Math. Comput. 218(12), 6727-6732 (2012)

5. Altun, I, Durmaz, G: Some fixed point results in cone metric spaces. Rend. Circ. Mat. Palermo 58, $319-325$ (2009)

6. Shatanawi, W: Some coincidence point results in cone metric spaces. Math. Comput. Model. 55, 2023-2028 (2012)

7. Shatanawi, W: On $w$-compatible mappings and common coincidence point in cone metric spaces. Appl. Math. Lett. 25, 925-931 (2012)

8. Agarwal, RP, El-Gebeily, MA, O'Regan, D: Generalized contractions in partially ordered metric spaces. Appl. Anal. 87, 109-116 (2008)

9. Altun, I: Some fixed point theorems for single and multivalued mappings on ordered non-Archimedean fuzzy metric spaces. Iranian J. Fuzzy Syst. 7(1), 91-96 (2010)

10. Aydi, H, Shatanawi, W, Postolache, M, Mustafa, Z, Tahat, N: Theorems for Boyd-Wong type contractions in ordered metric spaces. Abstr. Appl. Anal. 2012, ID 359054 (2012)

11. Aydi, H, Karapınar, E, Postolache, M: Tripled coincidence point theorems for weak $\varphi$-contractions in partially ordered metric spaces. Fixed Point Theory Appl. 2012, ID 44 (2012)

12. Berinde, $\mathrm{V}$ : Generalized coupled fixed point theorems for mixed monotone mappings in partially ordered metric spaces. Nonlinear Anal. 74, 7347-7355 (2011)

13. Chandok, S, Postolache, M: Fixed point theorem for weakly Chatterjea-type cyclic contractions. Fixed Point Theory Appl. 2013, ID 28 (2013)

14. Rezapour, Sh, Amiri, P: Some fixed point results for multivalued operators in generalized metric spaces. Comput. Math. Appl. 61, 2661-2666 (2011)

15. Shatanawi, W, Postolache, M: Common fixed point results of mappings for nonlinear contractions of cyclic form in ordered metric spaces. Fixed Point Theory Appl. 2013, ID 60 (2013)

16. Shatanawi, W, Samet, B: On $(\psi, \varphi)$-weakly contractive condition in partially ordered metric spaces. Comput. Math. Appl. 62(8), 3204-3214 (2011)

17. Zhilong, L: Fixed point theorems in partially ordered complete metric spaces. Math. Comput. Model. 54, 69-72 (2011)

18. Shatanawi, W, Postolache, M: Coincidence and fixed point results for generalized weak contractions in the sense of Berinde on partial metric spaces. Fixed Point Theory Appl. 2013, ID 54 (2013)

19. Menger, K: Statistical metrics. Proc. Natl. Acad. Sci. USA 28, 535-537 (1942)

20. Aydi, $\mathrm{H}$, Postolache, M, Shatanawi, W: Coupled fixed point results for $(\psi, \phi)$-weakly contractive mappings in ordered G-metric spaces. Comput. Math. Appl. 63(1), 298-309 (2012)

21. Shatanawi, W, Postolache, M: Some fixed point results for a G-weak contraction in G-metric spaces. Abstr. Appl. Anal. 2012, ID 815870 (2012)

22. Grabiec, M: Fixed points in fuzzy metric spaces. Fuzzy Sets Syst. 27, 385-389 (1988)

23. Gregori, V, Sapena, A: On fixed point theorems in fuzzy metric spaces. Fuzzy Sets Syst. 125, 245-252 (2002)

24. Kramosil, O, Michalek, J: Fuzzy metric and statistical metric spaces. Kybernetica 11, 326-334 (1975)

25. Rafi, M, Noorani, MSM: Fixed point theorem on intuitionistic fuzzy metric spaces. Iranian J. Fuzzy Syst. 3(1), 23-29 (2006)

26. Zadeh, LA: Fuzzy sets. Inf. Control 8, 338-353 (1965)

27. George, A, Veeramani, P: On some results in fuzzy metric spaces. Fuzzy Sets Syst. 64, 395-399 (1994)

28. Park, JH: Intuitionistic fuzzy metric spaces. Chaos Solitons Fractals 22, 1039-1046 (2004)

29. Alaca, C, Turkoghlu, D, Yildiz, C: Fixed points in intuitionistic fuzzy metric spaces. Chaos Solitons Fractals 29 1073-1078 (2006) 
30. Atanassov, K: Intuitionistic fuzzy sets. Fuzzy Sets Syst. 20, 87-96 (1986)

31. Coker, D: An introduction to intuitionistic fuzzy metric spaces. Fuzzy Sets Syst. 88, 81-89 (1997)

32. Di Bari, C, Vetro, C: A fixed point theorem for a family of mappings in a fuzzy metric space. Rend. Circ. Mat. Palermo 52, 315-321 (2003)

33. Karayilan, $\mathrm{H}$, Telci, M: Common fixed point theorem for contractive type mappings in fuzzy metric spaces. Rend. Circ. Mat. Palermo 60, 145-152 (2011)

34. Miheț, D: A Banach contraction theorem in fuzzy metric spaces. Fuzzy Sets Syst. 144, 431-439 (2004)

35. Park, JS, Kwun, YC, Park, JH: A fixed point theorem in the intuitionistic fuzzy metric spaces. Far East J. Math. Sci. 16, 137-149 (2005)

36. Schweizer, B, Sklar, A: Statistical metric spaces. Pac. J. Math. 10, 314-334 (1960)

37. Haghi, RH, Postolache, M, Rezapour, S: On T-stability of the Picard iteration for generalized $\varphi$-contraction mappings. Abstr. Appl. Anal. 2012, ID 658971 (2012)

38. Berinde, V: On stability of some fixed point procedures. Bul. Stiint. Univ. Baia Mare Ser. B Fasc. Mat.-Inform. 18, 7-14 (2002)

doi:10.1186/1687-1812-2013-168

Cite this article as: Ionescu et al.: Fixed points of some new contractions on intuitionistic fuzzy metric spaces. Fixed Point Theory and Applications 2013 2013:168.

\section{Submit your manuscript to a SpringerOpen ${ }^{\circ}$ journal and benefit from:}

- Convenient online submission

- Rigorous peer review

Immediate publication on acceptance

- Open access: articles freely available online

- High visibility within the field

- Retaining the copyright to your article 